\title{
Should we redefine meiofaunal organisms? The impact of mesh size on collection of meiofauna with special regard to nematodes
}

\author{
C. Ptatscheck (iD) S. Gehner - W. Traunspurger
}

Received: 14 June 2020/ Accepted: 25 August 2020/Published online: 7 September 2020

(C) The Author(s) 2020

\begin{abstract}
Meiofaunal organisms are the predominant metazoans in benthic systems and important members of the benthic food web. They are defined by mesh size and specifically by their retention on a sieve with a $44-\mu \mathrm{m}$ mesh size. In this study, we examined the accuracy of this standard collection method by counting the number of meiobenthic individuals, life stages and nematode species in a sample. A filter cascade consisting of five different mesh sizes $(41 \mu \mathrm{m}$, $30 \mu \mathrm{m}, 20 \mu \mathrm{m}, 10 \mu \mathrm{m}$ and $1 \mu \mathrm{m}$ ) was used to fractionate a natural freshwater meiobenthic collection, and the individuals in each fraction were then counted. In line with the current definition of meiofauna, all tardigrades, microcrustaceans, chironomids and oligochaetes were retained by the largest mesh size, whereas $9 \%$ of the rotifers were first retained on the $30-\mu \mathrm{m}$ meshes. For nematodes, $23 \%$ were not retained on the $41-\mu \mathrm{m}$ meshes and individuals were collected even from the $1-\mu \mathrm{m}$ fraction. With declining mesh size, the yield of retained nematodes increased,
\end{abstract}

Handling Editor: Télesphore Sime-Ngando.

Electronic supplementary material The online version of this article (https://doi.org/10.1007/s10452-020-09798-2) contains supplementary material, which is available to authorized users.

C. Ptatscheck $(\varangle) \cdot$ S. Gehner · W. Traunspurger

Bielefeld University, Animal Ecology, Konsequenz 45,

33615 Bielefeld, Germany

e-mail: christoph.ptatscheck@uni-bielefeld.de the age structure shifted to juveniles, evenness declined, and the species composition changed. As all of these findings were significant, this study therefore shows that the current definition of meiofauna is not sufficient to encompass the entire spectrum of meiofauna present in a sample and may result in misleading assessments of the diversity and composition of these organisms. We therefore propose that, especially for nematodes, a definition based on a smaller mesh size (at least $20 \mu \mathrm{m}$ ) is more appropriate.

Keywords Benthos - Nematodes - Diversity · Species composition $\cdot$ Age structure $\cdot$ Mesh size

\section{Introduction}

The term "meiobenthos" or "meiofauna" is well established in aquatic biology and was first used by Mare (1942) to describe the smallest metazoans that colonize sediments and other substrates of aquatic habitats (e.g., microcrustaceans, rotifers and nematodes). According to Higgins and Thiel (1988), meiobenthic organisms are those that pass through a net with a mesh size of $1000 \mu \mathrm{m}$ and which are held back by nets of $42-\mu \mathrm{m}$ mesh size. Giere (2009) later defined limit values for meiofauna of $500 \mu \mathrm{m}$ and $44 \mu \mathrm{m}$. Through a literature search on the databases Google Scholar (last search: 17th February 2020), we 
obtained 100 studies, all of them published within the last 40 years (1980-2020), that investigated meiofaunal structure in permanent freshwater habitats while also noting the mesh size used to collect the organisms (keywords: freshwater meiofauna/meiobenthos or meiofauna/meiobenthos community + stream or lake). In $60 \%$ of these studies, meiofauna was collected with a minimum mesh size in line with that used by Giere (2009) or even smaller $(\leq 44 \mu \mathrm{m})$, whereas many of the other studies relied on much larger (up to 100- $\mu \mathrm{m}$ ) meshes (Fig. 1). Studies in which meiofauna was mentioned only casually, for example as bycatch during plankton sampling, were not taken into account, but we noted that the mesh sizes used by the respective authors were up to $250 \mu \mathrm{m}$.

The classification of meiofauna is not based on taxon membership but on body size and even on body form and flexibility. For example, a nematode of $1 \mathrm{~mm}$ body length or a soft-bodied rotifer is able to pass through a net with a mesh size of $500 \mu \mathrm{m}$, which is impossible for a more spherically shaped, hard bodied Daphnia, whose average body length is also $1 \mathrm{~mm}$. However, Giere (2009) showed that the capture success of meiofauna and especially of nematodes could be greatly improved by the use of a smaller mesh size, i.e., $31 \mu \mathrm{m}$ rather than $44 \mu \mathrm{m}$ (e.g., for meiofauna from deep-sea environments). Previous studies had shown that juvenile nematodes (Caenorhabditis elegans), which have an average body length of $0.3 \mathrm{~mm}$,

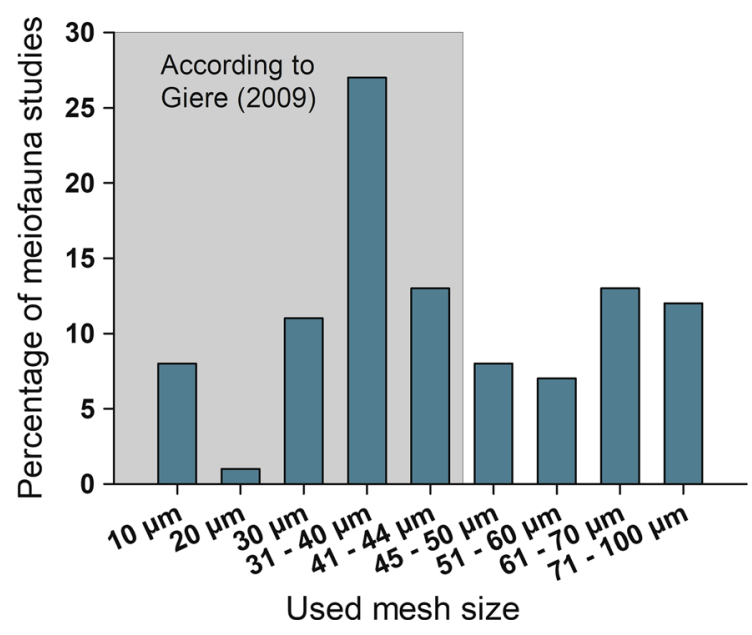

Fig. 1 Percentage distribution of the mesh sizes used in studies ( $n=100)$ on the composition of the meiofauna communities from the period 1980-2020 are not retained by nets with a mesh size of $35 \mu \mathrm{m}$ (Kreuzinger-Janik et al. 2019; Ptatscheck et al. 2015) or even by those with 5- $\mu$ m meshes (Kreuzinger-Janik et al. 2019). According to Strayer (1985), the chosen mesh size has a strong influence on the results of meiofaunal examinations.

Meiobenthic organisms are an inherent component of all aquatic habitats. They are present in soft and hard substrates of freshwaters, including lakes, streams, cave waters and groundwater as well as in marine habitats (Beier and Traunspurger 2001; Bergtold and Traunspurger 2004; Hakenkamp et al. 1994; Heip et al. 1985; Muschiol et al. 2015; Peters and Traunspurger 2005; Traunspurger 2000; Traunspurger et al. 2012). Even temporary water bodies are colonized by numerous meiobenthic taxa within just a few days (Devetter 2004; Ptatscheck and Traunspurger 2014; Zotz and Traunspurger 2016). In streams, lakes and marine environments, up to $82 \%$, $92 \%$ and $99 \%$ of metazoans are represented by meiofauna (Gerlach 1971; Majdi et al. 2017; Nalepa and Quigley 1983; Robertson et al. 2000; SchmidAraya et al. 2002; Tod and Schmid-Araya 2009; Traunspurger et al. 2019).

Rotifers (in freshwater), copepods (in marine environments) and nematodes are usually dominating within meiofauna, but also other microcrustaceans, small annelids as well as tardigrades and chironomid larvae are frequent and diverse meiobenthic representatives (Giere 2009; Majdi et al. 2017; Reiss and Schmid-Araya 2008; Stead et al. 2003; Traunspurger et al. 2012). For example, in a sample obtained from the periphyton of different lakes and containing over 1300 meiobenthic organisms per $\mathrm{cm}^{2}$, Schroeder et al. (2012a) found mostly rotifers $(26 \%)$ and nematodes (58\%), with the latter represented by 48 species (Schroeder et al. 2012b). In the study by Beier and Traunspurger (2003a, b), 71 and 113 nematode species were identified in $\sim 100 \mathrm{~cm}^{3}$ of sediment $\left(26-\mathrm{cm}^{2}\right.$ sediment area) obtained from two streams during the course of the year. In the sediment of Lake Königssee, 116 species were detected (Traunspurger 1996a, b), and in Lake Obersee a 3-year study yielded 152 nematode species (Michiels and Traunspurger 2004; 2005).

The ecosystem function of meiofauna is often greatly underestimated, as the contributions of these organisms to trophic interactions, nutrient cycling and food web are important (Hakenkamp and Morin 2000; 
Majdi et al. 2017; Majdi and Traunspurger 2015; Schmid-Araya and Schmid 2000). In lotic and lentic environments, meiofauna account for up to $50 \%$ of total secondary production (Bergtold and Traunspurger 2005; Reiss and Schmid-Araya 2010; Stead et al. 2005). Furthermore, meiofauna can serve as a reliable indicator of environmental pollution (Beier and Traunspurger 2001; Höss et al. 2011; Zeppilli et al. 2015). All these investigations benefit from a correct assessment of abundance of meiofauna organisms.

Our methodologically based study examined the freshwater meiofaunal organisms retained by sieving. Specifically, we asked whether, regardless of the extraction method and sampled habitat, all extracted taxa and life stages of this group could be completely retained by sieving according to the prescribed size limits? The results validated the recommendation of Giere (2009) that meiofauna and especially nematodes could be more completely collected by the use of a 31- $\mu \mathrm{m}$ mesh. Therefore, a suspension containing a natural meiofaunal community was filtered using a five-stage filter cascade employing mesh sizes of $41 \mu \mathrm{m}, 30 \mu \mathrm{m}, 20 \mu \mathrm{m}, 10 \mu \mathrm{m}$ and $1 \mu \mathrm{m}$. We expected that (H1) larger organisms, including chironomids, oligochaetes and hard bodied taxa such as microcrustaceans, would be retained by the $41-\mu \mathrm{m}$ mesh, whereas (H2) soft-bodied rotifers and especially nematodes, with their long, slender shapes, would partially pass through. We then focused on nematodes, the most abundant meiobenthic group, and hypothesized that (H3) the current definition of meiofauna is insufficient to reflect the real composition of nematode communities in a sample because it results in the omission of juvenile stages and possibly even some species.

\section{Materials and methods}

Meiofaunal organisms were extracted from the streambed of the Furlbach, a sandy headwater-stream (predominant grain size $<250 \mu \mathrm{m}$ ) with a low detritus content, and the littoral sediment of the Sandforther See (Lake Sandforther), a quarry pond with fine sandy and muddy sediment (predominant grain size $<250 \mu \mathrm{m}$ ). Both water bodies are located in North Rhine-Westphalia, Germany, and were chosen because their high meiofaunal density and high diversity of nematodes are well established. Sampling was conducted in February 2019 during a single day. Shovels were used to transfer the top $10 \mathrm{~cm}$ of the sediments into buckets, which were then filled with habitat water. After the samples had been mixed by hand, the supernatants were decanted through a sieve with a mesh size of $10 \mu \mathrm{m}$ and a diameter of $\varnothing 14.2 \mathrm{~cm}$ (polyamide fabric). Most of the sand particles remained in the bucket. Additionally, submerged moss was collected along the watercourse of the Furlbach, thoroughly rinsed with tap water and filtered (10 $\mu \mathrm{m}$ mesh size, $\varnothing 14.2 \mathrm{~cm}$, polyamide fabric). All retained components from the sediments of the two habitats and the Furlbach moss were pooled $(n=1)$, preserved in formaldehyde (final concentration: $4 \%$ ) and stained with rose Bengal. For this study, $\sim 900$ $\mathrm{ml}$ of concentrated sediment, organic matter and the contained organisms were used. Meiofauna were extracted from the remaining sediment and organic particles by density centrifugation (LudoxTM50, Sigma-Aldrich, Munich, Germany; $1.14 \mathrm{~g} \mathrm{ml}^{-1}$ ) according to Pfannkuche and Thiel (1988), using a six-fold quantity of Ludox. The resulting suspension was divided into ten 40-ml replicates. These were filtered through a cascade of five polyamide sieves of decreasing mesh size: $41 \mu \mathrm{m}(\varnothing 6.4 \mathrm{~cm}), 30 \mu \mathrm{m}(\varnothing$ $6.4 \mathrm{~cm}), 20 \mu \mathrm{m}(\varnothing 6.4 \mathrm{~cm}), 10 \mu \mathrm{m}(\varnothing 14.2 \mathrm{~cm})$ and $1 \mu \mathrm{m}(\varnothing 18.8 \mathrm{~cm})$ (open mesh area: $31 \%, 20 \%, 14 \%$, $4 \%, 1 \%)$. The sieves were carefully flushed with $600 \mathrm{ml}(41-\mu \mathrm{m}$ sieve) or $200 \mathrm{ml}$ (30- to $1-\mu \mathrm{m}$ sieves) of tap water from a beaker. The filtering process was accelerated by lightly tapping the sieve frames, but not by stirring or the use of a water jet. Only in the case of the $1-\mu \mathrm{m}$ sieves did we touch the underside of the mesh, gently dislodging trapped material using circular movements made with our fingers. After each use, the sieves were cleaned in an ultrasonic bath (30 min, $35 \mathrm{kHz}$ ). Each fraction was thoroughly washed from the sieve with tap water from a wash bottle and placed in gridded Petri dishes. All meiofauna were counted under a Leica L2 stereomicroscope $(40 \times$ magnification). 100 nematodes per sample and per sieve were prepared using the methods of Seinhorst $(1959,1962)$. When the number of nematodes was less than 100, all individuals were prepared. Nematodes were identified to the species level based on Leica Dialux microscopy observations $(1250 \times$ magnification) according to the criteria of Andrássy (2005, 2007, 2009), Loof et al. 
$(1999,2001)$ and references herein and classified into juvenile and adult individuals.

Data analysis

It was assumed that all organisms retained by a sieve with a particular mesh size would be retained by all sieves with smaller mesh sizes. Thus, for the data analysis, cumulative organism and species numbers determined from the respective sieve and from all larger mesh sizes were used to evaluate the efficiencies of the five sieves (cumulative fractionation).

The evenness $\left(E_{\mathrm{var}}\right)$ of the nematode community was calculated according to Smith and Wilson (1996).

Data with a confirmed normal distribution (Kolmogorov-Smirnov test) and homogeneity of variance (Levene test) were subjected to ANOVA and Tukey post hoc tests to compare the five fractions with respect to the percentage of juvenile nematodes, nematode species number and evenness. These tests were performed using Sigmaplot (version 12; SYSTAT Software, San Jose, California).

Differences in the nematode species composition of the five fractions were investigated using an analysis of similarity (ANOSIM). The resulting $R$-values (0-1) revealed differences in the nematode species composition in the fractions obtained with the five mesh sizes. $R$-values near 0 indicate no separation, while larger $R$-values suggest separation between groups. In addition, the percentage dissimilarity between the fractions was determined using an analysis of similarity percentages (SIMPER). Nematode composition was clustered using non-metric multi-dimensional scaling (nMDS). All techniques were based on a Bray-Curtis similarity using untransformed data. The analyses were carried out using the Primer 5 (PRIMER-E Ltd., 2001) software package.

\section{Results}

The mean number of organisms (10 replicates) obtained from the five different sieves was 13,944.7 $( \pm 2224.0, \mathrm{SD})$. While rotifers $(82.9 \% \pm 2.9 \%$, mean $\pm \mathrm{SD})$ and nematodes $(14.4 \% \pm 2.4 \%$, mean $\pm \mathrm{SD}$ ) dominated, other typical meiobenthic taxa, such as microcrustaceans and oligochaetes, were also present (Table 1).
Tardigrades, microcrustaceans, chironomids and oligochaetes were completely retained by the $41-\mu \mathrm{m}$ meshes. In the case of rotifers, 9.2\% $( \pm 3.2, \mathrm{SD})$ passed through but were completely retained on the $30-\mu \mathrm{m}$ meshes. The only meiofaunal taxon collected from all five sieves was nematodes: $77.0 \%( \pm 6.1 \%$, $\mathrm{SD})$ were trapped on the $41-\mu \mathrm{m}$ mesh, $85.4 \%$ $( \pm 4.3 \%, \mathrm{SD})$ on $30-\mu \mathrm{m}$ mesh, $90.4 \%( \pm 3.1 \%, \mathrm{SD})$ on $20-\mu \mathrm{m}$ mesh, $97.1 \%$ ( $\pm 3.1 \%$, SD) on $10-\mu \mathrm{m}$ mesh. $2.9 \%( \pm 3.0 \%, \mathrm{SD})$ passed through the $10-\mu \mathrm{m}$ mesh and were retained by the $1-\mu \mathrm{m}$ mesh (Table 1 ).

4202 of the nematodes retained on the five sieves could be assigned to 75 species. The dominant species were Eumonhystera vulgaris $(49.5 \% \pm 1.7 \%$, SD) and Eumonhystera pseudobulbosa $(13.1 \% \pm 1.6 \%)$. All other species were detected at $<4.0 \%$. Sixteen species, including the predominant taxa, were found in every replicate, while 20 species were collected from only one replicate. The total nematode composition of the sample is listed in Table S1.

With decreasing mesh size, the number of collected nematode species increased from an average of 26.4 $(41 \mu \mathrm{m})$ to 35.5 species $(1 \mu \mathrm{m})$ (Table 2$)$. The differences between the number of species collected on the $41-\mu \mathrm{m}$ sieve and all sieves with smaller mesh sizes were significant (Tukey test, all tested pairs: $p<0.001$ ) (Table 3). By contrast, the evenness decreased with decreasing mesh size, with significant differences between all fractions with the exception of those derived from the $10-\mu \mathrm{m}$ and $1-\mu \mathrm{m}$ meshes (Tukey test, all tested pairs: $p<0.01$ ) (Table 3). An analysis of the age distribution of the nematodes in the different fractions revealed a significant increase in the number of juveniles retained on the smaller meshes (Table 2). Thus, whereas on sieves with a $41-\mu \mathrm{m}$ mesh size, juveniles accounted for $56.5 \%( \pm 4.4 \%$, SD) of the collected nematodes, on the $1-\mu \mathrm{m}$ meshes the percentage increased to $81.3 \%( \pm 2.6 \%)$. With the exception of the $10-\mu \mathrm{m}$ and $1-\mu \mathrm{m}$ meshes, the differences between all fractions were significant (Tukey test, all tested pairs: $p<0.05$ ) (Table 3).

The nMDS plot (Fig. 2) clearly showed the clustering of the nematode species composition of the five fractions. In particular, the nematodes from the $41 \mu \mathrm{m}$ meshes were separated from the other groups, while the $10-\mu \mathrm{m}$ and $1-\mu \mathrm{m}$ fractions overlapped each other. These results were supported by the ANOSIM (Table 4), which showed no differences in nematode species composition between the fractions from the 
Table 1 Initial composition (density in the entire sample and percentage) of the investigated meiofaunal organisms and their cumulative fractionation on sieves with five different mesh sizes
The mean of ten replicates is shown, with the SD in parentheses

\begin{tabular}{|c|c|c|c|c|c|c|c|}
\hline \multirow[t]{2}{*}{ Taxon } & \multirow[t]{2}{*}{ Initial density } & \multirow[t]{2}{*}{ Percentage } & \multicolumn{5}{|c|}{ Percentage of organisms on the sieves } \\
\hline & & & $41 \mu \mathrm{m}$ & $30 \mu \mathrm{m}$ & $20 \mu \mathrm{m}$ & $10 \mu \mathrm{m}$ & $1 \mu \mathrm{m}$ \\
\hline Nematodes & $\begin{array}{l}1994.2 \\
( \pm 291.8)\end{array}$ & $\begin{array}{l}14.42 \\
( \pm 2.39)\end{array}$ & $\begin{array}{l}77.0 \\
( \pm 6.1)\end{array}$ & $\begin{array}{l}85.4 \\
( \pm 4.3)\end{array}$ & $\begin{array}{l}90.4 \\
( \pm 3.1)\end{array}$ & $\begin{array}{l}97.1 \\
( \pm 3.0)\end{array}$ & $\begin{array}{l}100.0 \\
( \pm 0.0)\end{array}$ \\
\hline Rotifers & $\begin{array}{l}11585.1 \\
( \pm 2142.7)\end{array}$ & $\begin{array}{l}82.88 \\
( \pm 2.94)\end{array}$ & $\begin{array}{l}90.8 \\
( \pm 3.2)\end{array}$ & $\begin{array}{l}100 \\
( \pm 0.0)\end{array}$ & - & - & - \\
\hline Tardigrades & $\begin{array}{l}3.9 \\
( \pm 3.7)\end{array}$ & $\begin{array}{l}0.03 \\
( \pm 0.03)\end{array}$ & $\begin{array}{l}100.0 \\
( \pm 0.0)\end{array}$ & - & - & - & - \\
\hline Copepods/nauplii & $\begin{array}{l}36.1 \\
( \pm 6.4)\end{array}$ & $\begin{array}{l}0.27 \\
( \pm 0.07)\end{array}$ & $\begin{array}{l}100.0 \\
( \pm 0.0)\end{array}$ & - & - & - & - \\
\hline Ostracods & $\begin{array}{l}4.3 \\
( \pm 2.8)\end{array}$ & $\begin{array}{l}0.03 \\
( \pm 0.02)\end{array}$ & $\begin{array}{l}100.0 \\
( \pm 0.0)\end{array}$ & - & - & - & - \\
\hline Cladocerans & $\begin{array}{l}4.6 \\
( \pm 2.6)\end{array}$ & $\begin{array}{l}0.03 \\
( \pm 0.02)\end{array}$ & $\begin{array}{l}100.0 \\
( \pm 0.0)\end{array}$ & - & - & - & - \\
\hline Chironomids & $\begin{array}{l}55.7 \\
( \pm 15.6)\end{array}$ & $\begin{array}{l}0.41 \\
( \pm 0.15)\end{array}$ & $\begin{array}{l}100.0 \\
( \pm 0.0)\end{array}$ & - & - & - & - \\
\hline Oligochaetes & $\begin{array}{l}260.8 \\
( \pm 69.5)\end{array}$ & $\begin{array}{l}1.93 \\
( \pm 0.66)\end{array}$ & $\begin{array}{l}100.0 \\
( \pm 0.0)\end{array}$ & - & - & - & - \\
\hline Total & $\begin{array}{l}13,944.7 \\
( \pm 2,224.0)\end{array}$ & $\begin{array}{l}100 \\
( \pm 0.00)\end{array}$ & - & - & - & - & - \\
\hline
\end{tabular}

Table 2 Cumulative nematode species number, evenness and percentage of juveniles collected from the five sieves differing in their mesh size

\begin{tabular}{llll}
\hline Mesh size & $\begin{array}{l}\text { Species } \\
\text { number }\end{array}$ & $\begin{array}{l}\text { Percentage } \\
\text { juveniles }\end{array}$ & Evenness \\
\hline $41 \mu \mathrm{m}$ & 26.4 & 56.5 & 0.59 \\
& $( \pm 3.4)$ & $( \pm 4.4)$ & $( \pm 0.03)$ \\
$30 \mu \mathrm{m}$ & 32.1 & 69.0 & 0.47 \\
& $( \pm 3.5)$ & $( \pm 3.0)$ & $( \pm 0.03)$ \\
$20 \mu \mathrm{m}$ & 33.6 & 74.3 & 0.41 \\
& $( \pm 3.0)$ & $( \pm 4.1)$ & $( \pm 0.03)$ \\
$10 \mu \mathrm{m}$ & 35.2 & 79.3 & 0.36 \\
& $( \pm 2.4)$ & $( \pm 3.3)$ & $( \pm 0.02)$ \\
$1 \mu \mathrm{m}$ & 35.5 & 81.3 & 0.35 \\
& $( \pm 2.5)$ & $( \pm 2.6)$ & $( \pm 0.03)$ \\
\hline
\end{tabular}

Mean $(n=10)$ and SD (in parenthesis)

$10-\mu \mathrm{m}$ and $1-\mu \mathrm{m}$ meshes $(R=0.008, p>0.5)$, but significant separation between those from all other meshes, in which the $R$-values ranged between 0.7 and $1(p<0.001)$.

With increasing differences between the mesh sizes, the dissimilarities between the composition of the retained nematode species increased as well. Thus, the largest dissimilarity $(65.6 \%)$ was that between the $41-\mu \mathrm{m}$ and $1-\mu \mathrm{m}$ fractions (Table 4 ). A comparison of adjacent mesh sizes showed a dissimilarity of $42.2 \%$ between the $41-\mu \mathrm{m}$ and $30-\mu \mathrm{m}$ sieves but smaller values $(<30 \%)$ for all other adjacent sieve pairs.

The dissimilarities between all tested pairs were mainly caused by the abundances of E. vulgaris, $E$. pseudobulbosa and Rhabdolaimus terrestris, whose contributions were between 36 and 56\%.

\section{Discussion}

Our study demonstrates that the mesh size commonly used for the collection of meiofauna does not result in the isolation of the entire community. Accordingly, the current definition of meiofauna, based on the mesh size used to obtain these organisms, does not accurately portray the whole meiofaunal community nor does it allow statements on species composition and diversity of nematodes and thus on the ecological relevance of this group.

Consistent with the long-standing definition of meiofauna and in accordance with hypothesis (H1), 
Table 3 Results of the analysis of variance (ANOVA) and post hoc Tukey test of differences in the cumulative number of nematode species, evenness and the percentage of juveniles determined from the five sieves with different mesh sizes $d f$ degrees of freedom, n.s. not significant, $* p<0.05$, $* * p<0.01, * * * p<0.001$

\begin{tabular}{lllll}
\hline & & Species number & Percentage juveniles & Evenness \\
\hline ANOVA & $d f$ & 4.00 & 4.00 & 4.00 \\
& $F$ & 15.28 & 79.26 & 131.60 \\
& $p$ & $<0.001$ & $<0.001$ & $<0.001$ \\
Post hoc & $41 \mu \mathrm{m}$ vs. $30 \mu \mathrm{m}$ & $* * *$ & $* * *$ & $* * *$ \\
& $41 \mu \mathrm{m}$ vs. $20 \mu \mathrm{m}$ & $* * *$ & $* * *$ & $* * *$ \\
& $41 \mu \mathrm{m}$ vs. $10 \mu \mathrm{m}$ & $* * *$ & $* * *$ & $* * *$ \\
& $41 \mu \mathrm{m}$ vs. $1 \mu \mathrm{m}$ & $* * *$ & $* * *$ & $* * *$ \\
& $30 \mu \mathrm{m}$ vs. $20 \mu \mathrm{m}$ & n.s. & $*$ & $* * *$ \\
& $30 \mu \mathrm{m}$ vs. $10 \mu \mathrm{m}$ & n.s. & $* * *$ & $* * *$ \\
& $30 \mu \mathrm{m}$ vs. $1 \mu \mathrm{m}$ & n.s. & $* * *$ & $* *$ \\
& $20 \mu \mathrm{m}$ vs. $10 \mu \mathrm{m}$ & n.s. & $*$ & $* * *$ \\
& $20 \mu \mathrm{m}$ vs. $1 \mu \mathrm{m}$ & n.s. & $* * *$ & n.s. \\
\hline
\end{tabular}

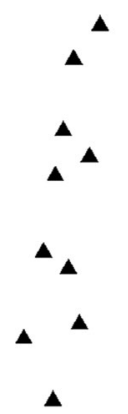

Fig. 2 nMDS plot (stress 0.07) of cumulative nematode species composition in the fractions obtained from sieves differing in their mesh size. The Bray-Curtis similarity was calculated without transformation

microcrustaceans, tardigrades, chironomids and oligochaetes were retained by the $41-\mu \mathrm{m}$ sieve. However, for the two most dominant taxa this was not the case, as $9 \%$ of rotifers passed through this sieve and nematodes were not completely retained even by the $10-\mu \mathrm{m}$ sieve (H2). Our results are in line with those of Hummon (1981), who was able to show that nematodes and rotifers were not retained by a $37-\mu \mathrm{m}$ sieve, while microcrustaceans and insect larvae did not pass through an even larger mesh $(62 \mu \mathrm{m})$. In our study, nematodes comprised $14 \%$ of the meiofaunal community, but in other investigations (Beier and Traunspurger 2001, 2003c; Reiss and Schmid-Araya 2008; Schroeder et al. 2012a) values of more than $90 \%$ were recorded. As shown in Table 1, a 23\% loss of the predominant taxon would be considerable.
Table 4 Comparisons of the cumulative nematode species composition determined in the fractions from the five mesh sizes

\begin{tabular}{lllll}
\hline Mesh size & $41 \mu \mathrm{m}$ & $30 \mu \mathrm{m}$ & $20 \mu \mathrm{m}$ & $10 \mu \mathrm{m}$ \\
\hline $30 \mu \mathrm{m}$ & $0.993 * * *$ & & & \\
& $(42.2)$ & & & \\
$20 \mu \mathrm{m}$ & $1.000^{* * *}$ & $0.735 * * *$ & & \\
& $(53.1)$ & $(24.9)$ & & \\
$10 \mu \mathrm{m}$ & $1.000^{* * *}$ & $0.999 * * *$ & $0.712 * * *$ & \\
& $(62.7)$ & $(36.6)$ & $(22.6)$ & \\
$1 \mu \mathrm{m}$ & $1.000^{* * *}$ & $1.000^{* * *}$ & $0.881 * * *$ & $0.008^{\text {n.s }}$. \\
& $(65.6)$ & $(40.8)$ & $(26.9)$ & $(14.5)$ \\
\hline
\end{tabular}

The $R$-values resulting from the ANOSIM and the percentage dissimilarity based on the Bray-Curtis analysis (in parentheses) are shown

n.s. not significant, $* * * p<0.001$

Between mesh sizes (global $R=0.731^{* * *}$ )

The largest differences in abundance and species composition were between the $41-\mu \mathrm{m}$ fraction and the fractions obtained with the smaller mesh sizes, and the smallest difference between the $10-\mu \mathrm{m}$ and $1-\mu \mathrm{m}$ fractions (Fig. 2, Tables 3, 4). In the preparation for the actual experiment, meiofauna were sampled and subsequently processed using $10-\mu \mathrm{m}$ sieves. Our results suggest that smaller individuals were therefore lost and if smaller mesh sizes had been used, the differences would have been even larger. However, the use of smaller mesh sizes in field or laboratory 
sampling of meiofauna is impracticable because of the fast blockage of the sieves by organic material or crystallized Ludox. Furthermore, part of the juveniles of 20 species and the adults of the three dominant species (Eumonhystera vulgaris, Eumonhystera pseudobulbosa, and Rhabdolaimus terrestris) were not retained even by the $10-\mu \mathrm{m}$ meshes. The minimum values reported for the body thickness of adult nematodes are $16.67 \mu \mathrm{m}$ (E. vulgaris), $9.71 \mu \mathrm{m}$ (E. pseudobulbosa) and $10.50 \mu \mathrm{m} \quad(R$. terrestris) (Andrássy 2005). Thus, the latter two species and especially the juvenile stages are able to pass through the $10-\mu \mathrm{m}$ meshes. These findings would account for the declining evenness obtained with the smaller mesh sizes. As shown by the SIMPER analysis, the three most common species were mainly responsible for the differences in nematode species composition. Because a high portion of these three species passed through the sieve with the largest mesh size, they predominated on finer meshes even though diversity and evenness declined. Thus, taken together, our results clearly show that nematodes retained by the $41-\mu \mathrm{m}$ mesh are only partly representative of the real community within the sample (H3).

In our study, we asked whether freshwater meiofaunal organisms are retained by meshes of the recommended sizes. To answer this fundamental question, we used suspended organisms already extracted by different methods such that less substrate was contained in the samples. Additionally, only dead organisms were sieved. Both the proportion of substrate and the condition of the organisms can affect extraction by sieving. Living organisms may actively twine through the meshes or hold onto it. For example, the appendages of some rotifer taxa serve as adhesion organs, while some nematode taxa produce caudal secretions that allow adherence to the substrate (Fontaneto and de Smet 2015; Majdi and Traunspurger 2015). Furthermore, living organisms can accumulate on large particles retained by the meshes.

These conditions explain why, despite previous $10-\mu \mathrm{m}$ sieving of the sediment with living organisms during meiofaunal collection, dead and extracted nematodes were not completely retained by meshes of the same size as used in the filter cascade. However, while Hummon (1981) filtered living meiofauna from sandy sediment, the percentage of nematodes and rotifers retained on the $37-\mu \mathrm{m}$ sieve was very similar to that retained on the $41-\mu \mathrm{m}$ meshes in this study.
Finally, it was beyond the scope of our study to evaluate the sieving of meiofauna as an extraction method, as our aim was to obtain a size-based definition of meiofauna.

In conclusion, our study showed that in investigations of meiofaunal communities the mesh sizes employed to collect these organisms must be smaller than those currently used to define meiofauna (44 $\mu \mathrm{m})$, because the latter do only partly efficiently retain nematodes and rotifers. As both groups frequently predominate in benthic systems, their loss would result in an underestimation and an inaccurate representation of the community structure of meiofauna. Over the last few decades, the ecologic importance of meiofauna has been pointed out in numerous studies. However, this claim can only be made using reliable datasets. Additionally, the wide range of mesh sizes $(10-100 \mu \mathrm{m})$ used in studies on freshwater meiofaunal communities conducted during the last 40 years (Fig. 1) make it difficult to compare the datasets, as already noted by Strayer in 1985 . For example, while in our study $97.1 \%$ of the nematodes and $100 \%$ of the rotifers in the sample were collected on a $10-\mu \mathrm{m}$ sieve, on $125-\mu \mathrm{m}$ meshes only $20.5 \%$ and $0.7 \%$ were retained (Hummon 1981). In $20 \%$ of the studies reviewed in Fig. 1, the mesh sizes were in between $10 \mu \mathrm{m}$ and $30 \mu \mathrm{m}$, indicating that, despite the increased workload (longer sieving) resulting from the use of smaller mesh sizes, such investigations are still be practicable.

Therefore, in agreement with the recommendations of Giere (2009) and Strayer (1985), we advocate that the minimum mesh size be reduced to at least $30 \mu \mathrm{m}$ or, even $20-\mu \mathrm{m}$, to obtain representative and comparable populations of meiofauna, especially when the nematode community is of scientific interest.

Acknowledgements We thank Birgit Gansfort for her help in analyzing the results.

Authors' contributions CP, SG and WT conceived the ideas and designed the methodology. CP and SG collected the data. CP analyzed the data. CP led the writing of the manuscript, and all authors discussed the manuscript.

Funding Open Access funding provided by Projekt DEAL.

Data availability After acceptance of the manuscript, data can be obtained from the author on request. 


\section{Compliance with ethical standards}

Conflict of interest Nothing to declare.

Open Access This article is licensed under a Creative Commons Attribution 4.0 International License, which permits use, sharing, adaptation, distribution and reproduction in any medium or format, as long as you give appropriate credit to the original author(s) and the source, provide a link to the Creative Commons licence, and indicate if changes were made. The images or other third party material in this article are included in the article's Creative Commons licence, unless indicated otherwise in a credit line to the material. If material is not included in the article's Creative Commons licence and your intended use is not permitted by statutory regulation or exceeds the permitted use, you will need to obtain permission directly from the copyright holder. To view a copy of this licence, visit http://creativecommons.org/licenses/by/4.0/.

\section{References}

Andrássy I (2005) Free-living nematodes of Hungary (Nematoda errantia). Pedozoologica Hungarica, Volume I. Hungarian Natural History Museum, Budapest

Andrássy I (2007) Free-living nematodes of Hungary (Nematoda errantia). Pedozoologica Hungarica, Volume II. Hungarian Natural History Museum, Budapest

Andrássy I (2009) Free-living nematodes of Hungary (Nematoda errantia). Pedozoologica Hungarica, Volume III. Hungarian Natural History Museum, Budapest

Beier S, Traunspurger W (2001) The meiofauna community of two small German streams as indicator of pollution. J Aquat Ecosyst Stress Recovery 8:387-405. https://doi. org/10.1023/A:1012965424527

Beier S, Traunspurger W (2003a) Seasonal distribution of freeliving nematodes in the Körsch, a coarse-grained submountain carbonate stream in southwest Germany. Nematology 5:481-504. https://doi.org/10.1163/ 156854103322683229

Beier S, Traunspurger W (2003b) Seasonal distribution of freeliving nematodes in the Krähenbach, a fine-grained submountain carbonate stream in southwest Germany. Nematology 5:113-136. https://doi.org/10.1163/ 156854102765216740

Beier S, Traunspurger W (2003c) Temporal dynamics of meiofauna communities in two small submountain carbonate streams with different grain size. Hydrobiologia 498:107-131. https://doi.org/10.1023/A:1026258607551

Bergtold M, Traunspurger W (2004) The benthic community in the profundal of Lake Brunnsee: seasonal and spatial patterns. Arch Hydrobiol 160:527-554. https://doi.org/10. 1127/0003-9136/2004/0160-0527

Bergtold M, Traunspurger W (2005) Benthic production by micro-, meio-, and macrobenthos in the profundal zone of an oligotrophic lake. J N Am Benthol Soc 24:321-329. https://doi.org/10.1899/03-038.1
Devetter M (2004) Invertebrate fauna of treeholes in relation to some habitat conditions in southern Bohemia (Czech Republic). Acta Soc Zool Bohem 68:161-168

Fontaneto D, de Smet WH (2015) Rotifera. In: Schmidt-Rhaesa A (ed) Gastrotricha, Cycloneuralia and Gnathifera, vol 3. Gastrotricha and Gnathifera. Walter de Gruyter $\mathrm{GmbH}$, Berlin, pp 217-300

Gerlach SA (1971) On the importance of marine meiofauna for benthos communities. Oecologia 6:176-190

Giere O (2009) Meiobenthology: the microscopic motile fauna of aquatic sediments, 2nd edn. Springer, Berlin

Hakenkamp CC, Morin A (2000) The importance of meiofauna to lotic ecosystem functioning. Freshw Biol 44:165-175. https://doi.org/10.1046/j.1365-2427.2000.00589.x

Hakenkamp CC, Palmer MA, James BR (1994) Metazoans from a sandy aquifer: dynamics across a physically and chemically heterogeneous groundwater system. Hydrobiologia 287:195-206. https://doi.org/10.1007/BF00010734

Heip C, Vincx M, Vranken G (1985) The ecology of marine nematodes. Oceanogr Mar Biol Ann Rev 23:399-489

Higgins RP, Thiel H (eds) (1988) Introduction to the Study of Meiofauna. Smithsonian Institution Press, Washington

Höss S, Claus E, von der Ohe PC, Brinke M, Güde H, Heininger $\mathrm{P}$, Traunspurger W (2011) Nematode species at risk-a metric to assess pollution in soft sediments of freshwaters. Environ Int 37:940-949. https://doi.org/10.1016/j.envint. 2011.03.013

Hummon WD (1981) Extraction by sieving: a biased procedure in studies of stream meiobenthos. Trans Am Microsc Soc 100:278-284. https://doi.org/10.2307/3225553

Kreuzinger-Janik B, Brüchner-Hüttemann H, Traunspurger W (2019) Effect of prey size and structural complexity on the functional response in a nematode- nematode system. Sci Rep 9:5696. https://doi.org/10.1038/s41598-019-42213-x

Loof PAA, Brauer A, Schwoerbel J, Zwick P (1999) Nematoda: Adenophorea (Dorylaimida), 1. Aufl. Süßwasserfauna von Mitteleuropa Nematoda, Nematomorpha, 2/2. Spektrum Akad. Verl., Heidelberg

Loof PAA, Brauer A, Schwoerbel J, Zwick P (2001) Nematoda: Secernentea (Tylenchida, Aphelenchida), 1. Aufl. Süßwasserfauna von Mitteleuropa Nematoda, Nematomorpha, 1/1. Spektrum Akad. Verl., Heidelberg

Majdi N, Traunspurger W (2015) Free-living nematodes in the freshwater food web: a review. J Nematol 47:28-44

Majdi N, Threis I, Traunspurger W (2017) It's the little things that count: meiofaunal density and production in the sediment of two headwater streams. Limnol Oceanogr 62:151-163. https://doi.org/10.1002//no.10382

Mare MF (1942) A study of a marine benthic community with special reference to the micro-organisms. J Mar Biol Assoc 25:517-554. https://doi.org/10.1017/S0025315400055132

Michiels I, Traunspurger W (2004) A three year study of seasonal dynamics of a zoobenthos community in a eutrophic lake. Nematology 6:655-669. https://doi.org/10.1163/ 1568541042843568

Michiels IC, Traunspurger W (2005) Seasonal variation of biodiversity and assemblage structure in freshwater nematodes. Arch Hydrobiol 163:183-194. https://doi.org/ 10.1127/0003-9136/2005/0163-0183

Muschiol D, Giere O, Traunspurger W (2015) Population dynamics of a cavernicolous nematode community in a 
chemoautotrophic groundwater system. Limnol Oceanogr 60:127-135. https://doi.org/10.1002/lno.10017

Nalepa TF, Quigley MA (1983) Abundance and biomass of the meiobenthos in Nearshore Lake Michigan with comparisons to the macrobenthos. J Great Lakes Res 9:530-547. https://doi.org/10.1016/S0380-1330(83)71926-X

Peters L, Traunspurger W (2005) Species distribution of freeliving nematodes and other meiofauna in littoral periphyton communities of lakes. Nematology 7:267-280. https:// doi.org/10.1163/1568541054879520

Pfannkuche O, Thiel H (1988) Sample processing. In: Higgins $\mathrm{RP}$, Thiel H (eds) Introduction to the Study of Meiofauna. Smithsonian Institution Press, Washington, pp 134-145

Ptatscheck C, Traunspurger W (2014) The meiofauna of artificial water-filled tree holes: colonization and bottom-up effects. Aquat Ecol 48:285-295. https://doi.org/10.1007/ s10452-014-9483-2

Ptatscheck C, Kreuzinger-Janik B, Putzki H, Traunspurger W (2015) Insights into the importance of nematode prey for chironomid larvae. Hydrobiologia 757:143-153. https:// doi.org/10.1007/s10750-015-2246-9

Reiss J, Schmid-Araya JM (2008) Existing in plenty: abundance, biomass and diversity of ciliates and meiofauna in small streams. Freshw Biol 53:652-668. https://doi.org/10. 1111/j.1365-2427.2007.01907.x

Reiss J, Schmid-Araya JM (2010) Life history allometries and production of small fauna. Ecology 91:497-507. https:// doi.org/10.1890/08-1248.1

Robertson AL, Rundle SD, Schmid-Araya JM (2000) Putting the meio- into stream ecology: current findings and future directions for lotic meiofaunal research. Freshw Biol 44:177-183. https://doi.org/10.1046/j.1365-2427.2000. 00592.x

Schmid-Araya JM, Schmid PE (2000) Trophic relationships: integrating meiofauna into a realistic benthic food web. Freshw Biol 44:149-163. https://doi.org/10.1046/j.13652427.2000.00594.x

Schmid-Araya JM, Hildrew AG, Robertson A, Schmid PE, Winterbottom J (2002) The importance of meiofauna in food webs: evidence from an acid stream. Ecology 83:1271-1285

Schroeder F, Traunspurger W, Pettersson K, Peters L (2012a) Temporal changes in periphytic meiofauna in lakes of different trophic states. J Limnol 71:216-227. https://doi. org/10.4081/jlimnol.2012.e23

Schroeder F, Peters L, Traunspurger W (2012b) Temporal variations in epilithic nematode assemblages in lakes of different productivities. Fundam Appl Limnol 181:143-157. https://doi.org/10.1127/1863-9135/2012/ 0332

Seinhorst JW (1959) A rapid method for the transfer of nematodes from fixative to anhydrous glycerin. Nematologica 4:67-69. https://doi.org/10.1163/187529259X00381

Seinhorst JW (1962) On the killing, fixation and transferring to glycerine of nematodes. Nematologica 8:29-32. https:// doi.org/10.1163/187529262X00981
Smith B, Wilson JB (1996) A consumer's guide to evenness indices. Oikos 76:70-82. https://doi.org/10.2307/3545749

Stead TK, Schmid-Araya JM, Hildrew AG (2003) All creatures great and small: patterns in the stream benthos across a wide range of metazoan body size. Freshw Biol 48:532-547. https://doi.org/10.1046/j.1365-2427.2003. 01025.x

Stead TK, Schmid-Araya JM, Hildrew AG (2005) Secondary production of a stream metazoan community: does the meiofauna make a difference? Limnol Oceanogr 50:398-403. https://doi.org/10.4319/1o.2005.50.1.0398

Strayer DL (1985) The benthic micrometazoans of Mirror lake, New Hampshire. Arch Hydrobiol Suppl 72:287-426

Tod SP, Schmid-Araya JM (2009) Meiofauna versus macrofauna: secondary production of invertebrates in a lowland chalk stream. Limnol Oceanogr 54:450-456. https://doi. org/10.4319/lo.2009.54.2.0450

Traunspurger W (1996a) Distribution of benthic nematodes in the littoral of an oligotrophic lake (Königssee, National Park Berchtesgaden, FRG). Arch Hydrobiol 135:393-412

Traunspurger W (1996b) Distribution of benthic nematodes in the littoriprofundal and profundal of an oligotrophic lake (Königssee, National Park Berchtesgaden, FRG). Arch Hydrobiol 135:557-575

Traunspurger W (2000) The biology and ecology of lotic nematodes. Freshw Biol 44:29-45. https://doi.org/10. 1046/j.1365-2427.2000.00585.x

Traunspurger W, Höss S, Witthöft-Mühlmann A, Wessels M, Güde H (2012) Meiobenthic community patterns of oligotrophic and deep Lake Constance in relation to water depth and nutrients. Fundam Appl Limnol 180:233-248. https://doi.org/10.1127/1863-9135/2012/0144

Traunspurger W, Wilden B, Majdi N (2019) An overview of meiofaunal and nematode distribution patterns in lake ecosystems differing in their trophic state. Hydrobiologia 847:2665-2679. https://doi.org/10.1007/s10750-01904092-1

Zeppilli D, Sarrazin J, Leduc D, Arbizu PM, Fontaneto D, Fontanier C, Gooday AJ, Kristensen RM, Ivanenko VN, Sørensen MV, Vanreusel A, Thébault J, Mea M, Allio N, Andro T, Arvigo A, Castrec J, Danielo M, Foulon V, Fumeron R, Hermabessiere L, Hulot V, James T, Langonne-Augen R, Le Bot T, Long M, Mahabror D, Morel Q, Pantalos M, Pouplard E, Raimondeau L, Rio-Cabello A, Seite S, Traisnel G, Urvoy K, van der Stegen T, Weyand M, Fernandes D (2015) Is the meiofauna a good indicator for climate change and anthropogenic impacts? Mar Biodivers 45:505-535. https://doi.org/10.1007/s12526-015-0359-z

Zotz G, Traunspurger W (2016) What's in the tank? Nematodes and other major components of the meiofauna of bromeliad phytotelms in lowland Panama. BMC Ecol 16:9. https:// doi.org/10.1186/s12898-016-0069-9

Publisher's Note Springer Nature remains neutral with regard to jurisdictional claims in published maps and institutional affiliations. 